\title{
تطوير المنشأت الرياضية بدولة الكويت من خلال المشاركة المجتمعية فى اطار تطبيق معايير جودة المنشأت
}

* د/ موضي عبد الله علي عامر الحصينان

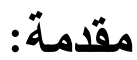

أن ممارسة الرياضة والارتقاء بمستوى اللياقة البدنية لدى أفراد المجتمع بدولة الكويت إلى

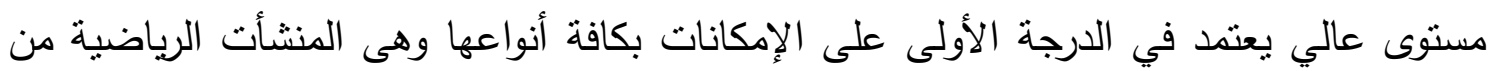
ملاعب وصالات رياضية، فكلما تزايدت وارتفعت هذه الإمكانات تزايدت مستوى اللياقة البدنية لاى

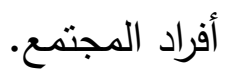
ومن أهم هذه الإمكانات المنشأت الرياضية التى يجب الاهتمام بها والعمل على تطويرها وتتميتها بالثراكة مع المنظمات المجتمعية وفقاً لحاجات المجتمع التى تقوم بخدمته هذه المنشأت. يذكر كلاً من مساعد الهارون (2013م)، إبراهيم عبد المقصود (2012م) أن المؤسسة الرياضية هى عبارة عن مؤسسات عمومية إدارية، تتحصر في تتظيم وتسير الممارسة الرياضية (التتافسية، الجماهير، المدرسية والجامعية) وتتكل أيضا المنشأت الرياضية في الملاعب الخاصة بكرة القدم وفي الصالات المتعدة الرياضات. (10: 216)، (1: 99) ويعرف سمير عبد الحميد (2012م) المنشأت الرياضية بأنها مؤسسات تربوية تهدف إلى إعداد الثباب والاهتمام بالنشء، ورعايته في ضوء السياسة العامة للاولة. (8: 2) ويضيف أحمد الفاضل (2015م) تختلف المنشأت الرياضية عن بعضها بناء على ما تحتويه من أماكن تتعلق بممارسة النشاطات الرياضية، ولهذا من الممكن تصنيفها إلى عدة أنواع وذلك من حيث الأهداف، الثكل العام، الرياضة (اللعبة)، القانونية، التباعية ونوعية الأرضية. (94:4)

ويوضح إبراهيم عبد المقصود وحسن الثافعى (2012م) بصفة عامة يوجد أربعة أنواع من المنشأت الرياضية هي المنشأت الداخلية مثل الصالات المغطاة وحمامات السباحة والمنشأت الخارجية مثل الملاعب الخارجية، وحدات خلع الملابس والاستحمام ودورات المياه والغرف والمرافق

* حاصلة على درجة الدكتوراه فى التربية البننية ورئيس قسم تربية بذنية بمنطقة الأحمدى التعليمية وزارة

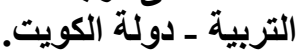


أن المنشأت الرياضية هى عبارة عن منشأت رياضية وملاعب وصالات رياضية تتشها

الدولة في المحافظات والمدن المختلفة وذلك لخدمة القطاع الرياضي من كافة جوانبه، بحيث يكون لها هيكل تتظيمي يتفق مع حجم هذه المؤسسة وأهدافها، بما يعود بالنفع لخدمة أفراد المجتمع وفقاً للأهداف العامة للاولة.

وتوضح كلاً من عفاف عبد المنعم (2008م)، آمنة مصطفى (2000م) إن إقامة المنشأت الرياضية لا يأتي عشوائياً بل لابد من وجود أساس علمي يدفع ويوجه ليمنح القائمين على العمل قوة دفع للارتقاء بالمنشأة والإمكانات الرياضية من أجل أفضل تحقيق لأغراضها التي أقيمت من بن

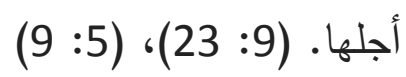
ويذكر إبراهيم مروان (2015م) أن أهداف المنشأت الرياضية إقامة فعاليات جميع الأنشطة الرياضية والتقافية والاجتماعية، محاولة جذب واحتواء الثباب لممارسة الأنشطة الرياضية بشكل متواصل ومنظم، رعاية الثباب وزيادة فاعليته في المجتمع، الاستفادة من الطاقات الثبابية وتوظيفها في خدمة المجتمع وتنظيم واستثمار وقت الفراغ لدى النشء والثباب لما فيه خدمة الفرد

والمجتمع. (3: (57) ويضيف روش Roche, (2014م) تتقسم المنشأت الرياضية إلى منشأت رياضية مفتوحة ومنشأت مغلقة وتخضع كلاً منهما إلى اثتراطات دولية في التصميم. (22: 1 1) ويتفق كلاً من ناصر دادي (2015م)، ديفرنس جاكويز Defrance Jacques (2013م) أن المنشأت الرياضية عبارة عن مؤسسات ينشئها المجتمع والهدف منها هو خدمة القطاع الرياضي من كافة جوانبه، بحيث يكون لها هيكل تتظيمي يتفق مع حجم هذه المؤسسة وأهدافها، بما يعود بالنفع لخدمة ذلك المجتمع متماثنياً مع أهدافه. (11: 83)، (17: 99 ويذكر كويل ومورو Coyle \& Morrow (2003م) هناك العديد من المبررات المنطقية وراء تطبيق فلسفة إدارة الجودة الثشاملة، منها ما تتطلق من أهمية تحسين مستوى الجودة سواءا كان

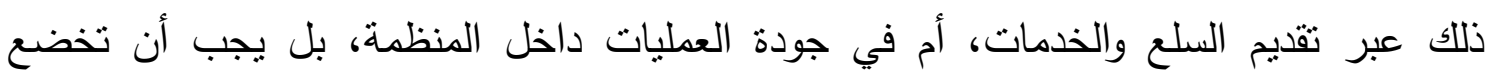
العمليات والأنشطة داخل المنظمة على أساس معايير الجودة. (15: 82) 
Karajewisky \& Ritzam

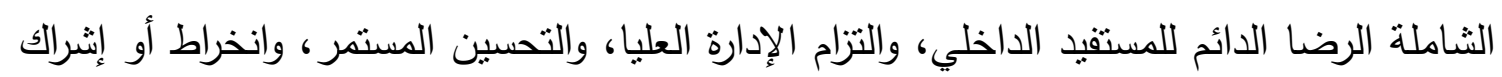

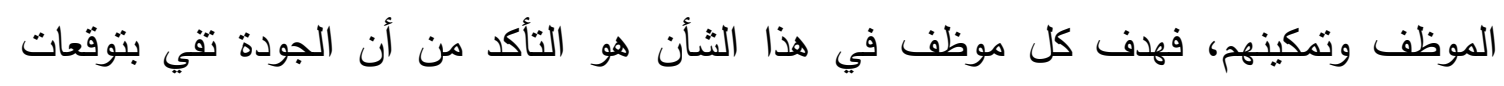
الثخص. (13: 9)، (19: 36)، (16:

ويرى بسترفيلد وآخرون Besterfield, et al., (2005م) أن نطبيق إدارة الجودة الثاملة قرار استراتيجي بيد الإدارة العليا، ويمس حاضر ومستقبل المنظمة. ويظهر التزام ودعم الإدارة

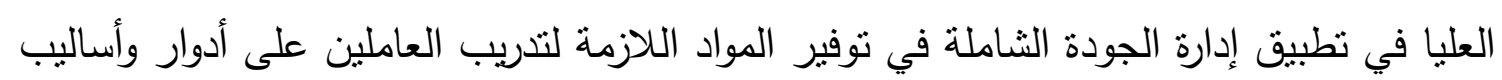
إدارة الجودة الثاملة، وإقامة ورش العمل، والندوات التي يمكن أن تزيد من وعي العاملين بمنهجها. (82:14)

تحرص دولة الكويت على إنثاء العديد من المنشأت الرياضية فى كل المحافظات والمدن المختلفة ويتتوع إنثاء هذه المنشأت الرياضية ما بين المنشأت الرياضية القانونية والأولمبية لإقامة دهنة

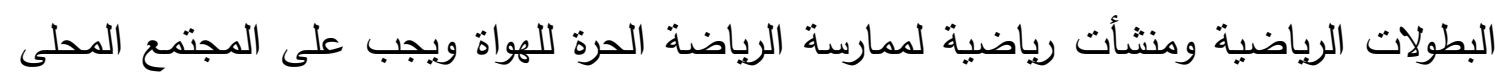
وعلى المنظمات المجتمعية الاهتمام بهذه المنشأت والعمل على نظويرها وتتميتها من خلال إستخدام أهداف وخصائص ووظائف منهج إدارة الجودة. وذلك لأن منهج إدارة الجودة منهج إدارى يهتم بنطوير وتتمية جميع العمليات الإدارية والفنية وكذلك الإمكانيات المادية داخل المؤسسات والمنظمات المختلفة.

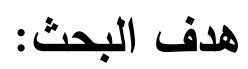

يهدف البحث إلى تطوير المنشأت الرياضية بدولة الكويت من خلال المشاركة المجتمعية فى اطار تطبيق معايير جودة المنشأت وذلك من خلال التعرف على: - طرق إدارة المنشأت الرياضية بدولة الكويت. - دور تطبيق معايير جودة المنشأت فى تطوير المنشأت الرياضية بدولة الكويت. تساؤلات البحث: - - ما هو دور تطبييق معايير جودة المنشأت فى نطوير المنشأت الرياضية بدولة الكويت؟ 


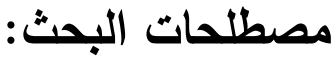

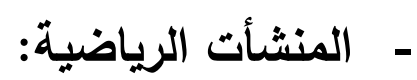

عرفت الهيئة العامة للثباب والرياضة (2015م) المنثأت الرياضية بأنها المرافق الرياضية

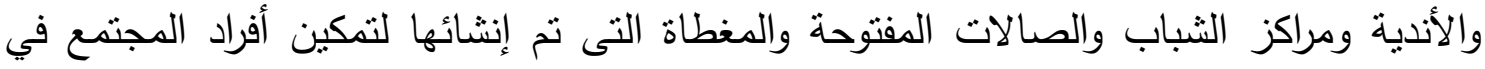
مراحل سنية مختلفة من ممارسة هواياتهم ونثاطاتهم الرياضية. (12: 2)

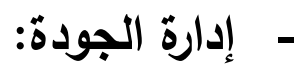

يعرف كلاً من روينز وكولتر Robbins \& Coulter (2005م)، هاشمي Hashmi (2005م) إدارة الجودة بأنها بأنها فلسفة إدارية تثمل كافة نثاطات المنظمة التي من خلالها يتم تحقيق احتياجات، وتوقعات العميل، والمجتمع، وتحقيق أهداف المنظمة كذلك بأكفأ الطرق واقلها تكلفة عن طريق الاستخدام الأمتل لطاقات جميع العاملين بدافع مستمر للتطوير. $(58: 18) ،(22: 21)$

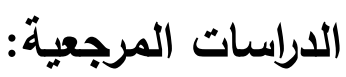

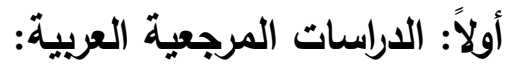

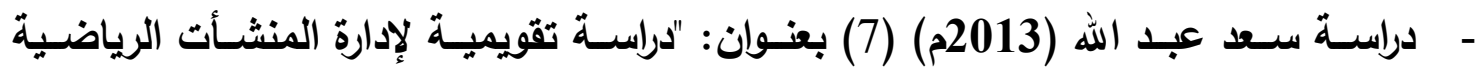

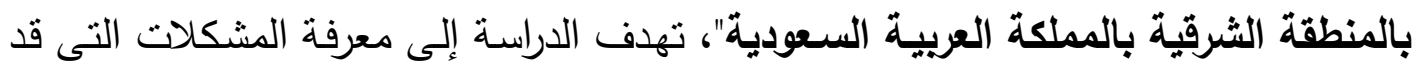

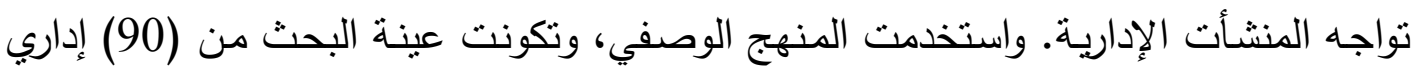

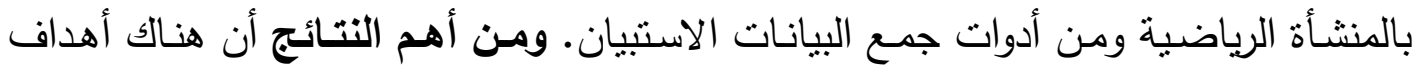
أمكن تحقيقها فى حين بعض الأهداف لم يتحقق وذلك بوجود معوقات في عملية التنفيذ.

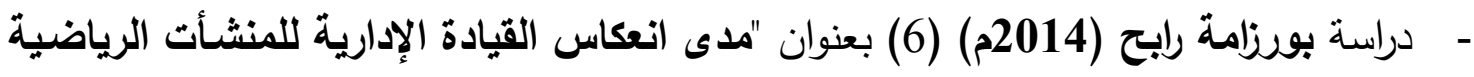

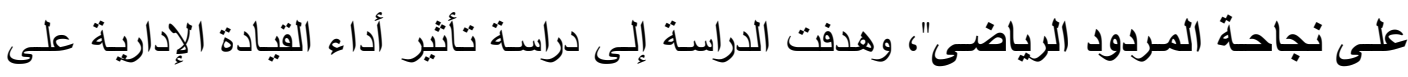

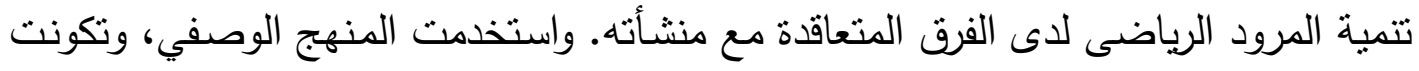
عينة البحث من (55) لاعبا ومن أدوات جمع البيانات الاستبيان. ومن أهم النتائج أن القيادة العادي

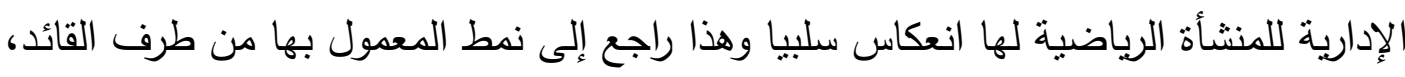
فإذا كانى مستبدا في ادارة المنثأة الرياضية فهذا ما ينعكس سلبا على أداء اللاعبين. 
ثانياً: الدراسات المرجعية الأجنبية: - دراسة كيم Kim (1997م) (20) بعنوان "تحديد الكفايات التى تخص العمل ذات الأهمية لمدراء المراكز الرياضية في جمهورية كوريا"، وهدفت الدراسة إلى تحديد الكفايات التى تخص العمل ذات الأهمية لمدراء المراكز الرياضية في جمهورية كوريا. واستخدت المنهج الوصفي، وتكونت عينة البحث من (1575) مدير فى المراكز الرياضية ومن أدوات جمع البيانات الاستيان. ومن أهم النتائج إن المستوى الإداري والوضع التتظيمي كان له تأثثر على الأهمية ذات العلاقة بالكفايات، منل إدارة المخاطر ، فهم الطبيعة الرياضية، الاتصالات، نطوير القيادة، وتحديد مصادر التمويل ذو أهية كبيرة.

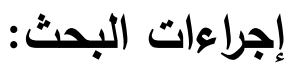

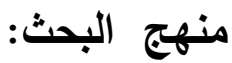

استخدمت الباحثة المنهج الوصفى بالأسلوب المسحى.

$$
\text { - مجتمع وعينة البحث: }
$$

يتمتل مجتمع البحث من جميع المسئولين عن المنشأت الرياضية بالمدن والأحياء. -

قد نم اختيار عينة البحث بالطريقة العشوائية من المسئولين عن المنشأت الرياضية، حيث تكونت عينة البحث من عدد (60) فرد وانقسمت إلى عينة أساسية وعددها (40) فرد وعينة إستطلاعية عددها (20) فرد ويوضح جدول (1) ذلك. جدول (1)

\begin{tabular}{|c|c|c|c|c|c|c|c|}
\hline \multicolumn{8}{|c|}{ توصيف عينة البحث } \\
\hline 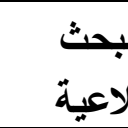 & الإند & | الأساسية | & عينة الب & تِّ الكلية & & العينة & \\
\hline$\%$ & عدد & $\%$ & عدد & $\%$ & عدد & & \\
\hline$\% 33,3$ & 20 & $\% 66,7$ & 40 & $\% 100$ & 60 & |الرياضـئئولين عــن المنتـــأت & 1 \\
\hline
\end{tabular}
توصيف عينة البحث 


\section{وسائل جمع البيانات:}

\section{- - المقابلة الشخصية (المقننة).

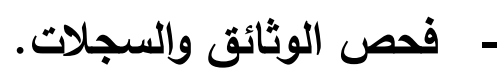 \\ -}

قامت الباحثة بتصميم استمارة استنيان تطوير المنشأت الرياضية بدولة الكويت من خلال المشاركة المجتمية فى اطار تطبيق معايير جودة المنشأت إعداد الباحثة. وقد تم تصميم استمارة الاستبيان فى ضوء أهداف البحث والغرض منها وذلك وفقاً للمراحل

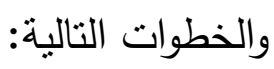

- تحديد محاور استمارة الاستبيان: قامت الباحثة بتحديد المحاور الخاصة باستمارة الاستبيان من خلال المحاور التى استتد عليها العلماء، والباحثين فيما يخص طرق إدارة المنشأت الرياضية وطرق ووسائل استخدام الأدوات والأجزة الرياضية فى رفع مستوى اللياقة البدنية وتم عرض هذه الدحاور بالدقابلة الثخصية على عدد (10) خبراء فى مجال الإدارة الرياضية. - تحديد عبارات محاور الاستبيان: قد قامت الباحثة بإعداد استمارة الاستبيان من خلال صياغة العبارات الأساسية لكل محور بما يتتاسب مع هذه المحاور بحيث تغطي هذه العبارات الجوانب المراد تحقيقها مع مراعاة تتاسب هذه العبارات مع طبيعة ومواصفات العينة. وثم قامت الباحثة بعرض استمارة الاستبيان مرة أخرى على عدد (10) خبراء في مجال الإدارة الرياضية لإبداء آرائهم في ددى تطابق عبارات كل محور ومدى ارتباط العبارات مع المحاور.

\section{الاراسة الاستطلاعية:}

قامت الباحثة بتطبيق استمارة الاستبيان علي العينة الاستطلاعية ويبلغ عددها (20) من المسئولين عن المنشأت الرياضية وذلك في الفترة من يوم 2015/11/1م إلى يوم 2015/12/5م وذلك لحساب المعاملات العلمية للاستبيان من صدق وثبات. 
قامت الباحثة بحساب الصدق بإستخدام نوعين من الصدق هما صدق المحتوى أو المضمون وصدق الاتساق الداخلي. - صدق المحتوى أو المضمون:

قامت الباحثة بحساب صدق المحتوى أو المضمون من خلال عرض استمارة الاستبيان على عدد من الخبراء في مجال الإدارة الرياضية لإبداء آرائهم في مدى تطابق عبارات كل محور ومدى ارتباط العبارات مع المحاور . - - مدق الاتساق الاخلي:

قامت الباحثة بحساب صدق الاتساق الداخلي لاستمارة الاستنيان عن طريق نطبيق الاستبيان على العينة الاسنطلاعية لحساب معامل الارتباط بين كل عبارة والمجمع الكلى للمحور التابع له العبارات وبين كل محور والمجموع الكلى لإستمارة الإستبيان ويوضح جدول (2) ذلك.

جدول (2) مدو (2)

معامل الارتباط بين كل محور والمجموع الكلى لإستمارة الإستبيان

$30=$ ن

\begin{tabular}{|c|c|c|}
\hline الإتباط & المحاور & P \\
\hline$* 0,663$ & |المحور الأول: نوافر الإمكانات المادية والبشرية للمنشأت الرياضية. & 1 \\
\hline$* 0,845$ & 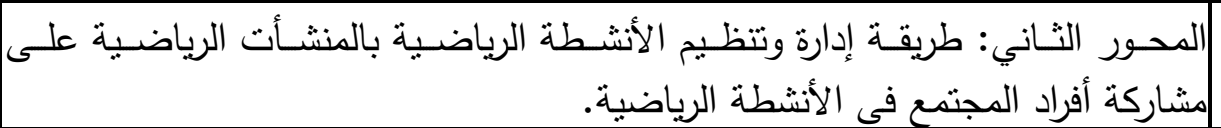 & 2 \\
\hline$* 0,752$ & الكحور الثالث: برامج الأنشطة الرياضية داخل المنشأت الرياضية. & 3 \\
\hline$* 0,684$ & المجموع الكلى لإستمارة الإستبيان & 4 \\
\hline
\end{tabular}

يتضح من جدول (2) معامل الارتباط بين كل محور والمجموع الكلى لإستمارة الإستيان،

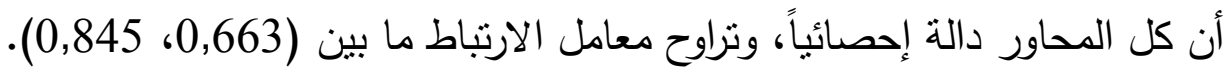
الثبات: - 1 - n

قامت الباحثة بحساب الثبات بإستخدام طريقة النطبيق وإعادة التطبيق وحساب معامل الإرتباط بين التطبيق الأول وإعادة النطبيق (النطبيق الثاني) لإستمارة الإستبيان. 


\section{- - التطبيق وإعادة التطبيق:}

قامت الباحثة بحساب معامل الارتباط باستخدام طريقة التطبيق وإعادة التطبيق، حيث قامت

الباحثة بتطبيق استمارة الاستبيان على العينة الاستطلاعية وإعادة تطبيق (النطبيق الثاني) إستمارة الإستبيان على نفس العينة بعد (15) يوم من تاريخ التطبيق الأول ويوضح جدول (3) ذلك.

$$
\text { جدول (3) منال }
$$

قيم معامل الارتباط بين التطبيق الأول والتطبيق الثاني

$30=\dot{0}$

\begin{tabular}{|c|c|c|}
\hline معامل الإرتباط & المحاور & $p$ \\
\hline$* 0,744$ & المحور الأول: نوافر الإمكانات المادية والبشرية للمنشأت الرياضية. & 1 \\
\hline$* 0,722$ & 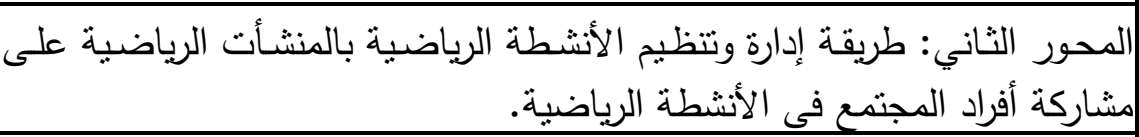 & 2 \\
\hline$* 0,744$ & المحور الثالث: برامج الأنشطة الرياضية داخل المنشأت الرياضية. & 3 \\
\hline$* 0,743$ & المجموع الكلى لإستمارة الإستبيان & 4 \\
\hline
\end{tabular}

ويتضح من جدول (3) أن قيم معامل الارتباط بين التطبيق الأول والتطبيق الثاني لإستمارة

الإستنيان ذات دلالة إحصائية، حيث تراوحت ما بين (0,722، 0,744)، مما يدل على ثبات

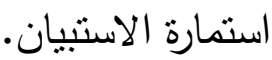

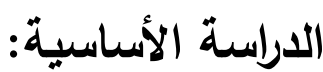

قامت الباحثة بتطبيق إستمارة الإستبيان النهائية علي العينة الأساسية المسحوبة من نفس المجتمع وعددها (40) من المسئولين عن المنشأت الرياضية وذلك في يوم 2015/12/15م إلى يوم 2016/2/1م وذلك لإيجاد المعالجات الإحصائية لإستمارة الإستيان.

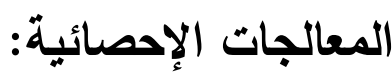

وقد تمت المعالجات الاحصائية باستخدام الاحصاء الوصفى عن طريق العطليات الاحصائية

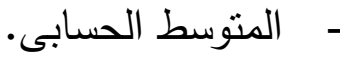

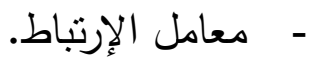


- - الإنحراف المعيارى. -

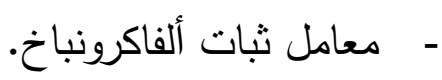

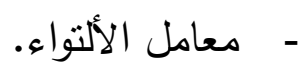

عرض ومناقشة النتائج:

عرض ومناقثة نتائج المحور الأول توافر الإمكانات المادية والبشرية للمنشأت الرياضية:

جدول (4)

التكرار والنسب المئوية والمتوسط الحسابي والإنحراف المعياري ومعامل الالتواء لعبارات

المحور الأول توافر الإمكانات المادية والبشرية للمنشأت الرياضية والحية المبارية

$40=ن$

\begin{tabular}{|c|c|c|c|c|c|c|c|c|c|}
\hline \multirow{2}{*}{ معامل الالتواء } & \multirow{2}{*}{ المعيارى } & \multirow{2}{*}{ الحستوسط } & \multicolumn{2}{|l|}{ 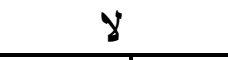 } & \multicolumn{2}{|c|}{ إلى حـ ما } & \multicolumn{2}{|c|}{ نعم } & \multirow[b]{2}{*}{ e } \\
\hline & & & $\%$ & s & $\%$ & s & $\%$ & s & \\
\hline $0,851-$ & 0,452 & 2,00 & $\% 20$ & 8 & $\% 10$ & 4 & $\% 70$ & 28 & 1 \\
\hline $1,033^{-}$ & 0,679 & 2,50 & $\% 15$ & 12 & $\% 10$ & 8 & $\% 75$ & 30 & 2 \\
\hline 0,877 & 0,810 & 1,60 & $\% 25$ & 10 & $\% 10$ & 4 & $\% 65$ & 26 & 3 \\
\hline 0,684 & 0,671 & 1,60 & $\% 15$ & 6 & $\% 20$ & 8 & $\% 65$ & 26 & 4 \\
\hline $0,602-$ & 0,790 & 2,300 & $\% 25$ & 10 & $\% 10$ & 4 & $\% 65$ & 26 & 5 \\
\hline 0,864 & 0,640 & 2,00 & $\% 15$ & 10 & $\% 10$ & 6 & $\% 75$ & 34 & 6 \\
\hline $1,45^{-}$ & 0,671 & 2,60 & $\% 30$ & 12 & $\% 35$ & 14 & $\% 35$ & 14 & 7 \\
\hline $1,55^{-}$ & 0,405 & 2,80 & $\% 5$ & 2 & $\% 10$ & 4 & $\% 85$ & 34 & 8 \\
\hline $1,567-$ & 0,640 & 2,00 & $\% 15$ & 10 & $\% 10$ & 6 & $\% 75$ & 34 & 9 \\
\hline 0,647 & 0,452 & 2,00 & $\% 10$ & 3 & $\% 15$ & 5 & $\% 80$ & 32 & 10 \\
\hline $1,033-$ & 0,679 & 2,5 & $\% 25$ & 10 & $\% 10$ & 4 & $\% 65$ & 26 & 11 \\
\hline $0,196^{-}$ & 0,841 & 2,100 & $\% 5$ & 2 & $\% 5$ & 2 & $\% 90$ & 36 & 12 \\
\hline 0,357 & 0,757 & 1,80 & صفر \% & صفر & $\% 5$ & 4 & $\% 90$ & 36 & 13 \\
\hline $0,602-$ & 0,790 & 2,30 & $\% 20$ & 8 & $\% 10$ & 4 & $\% 70$ & 28 & 14 \\
\hline $1,654-$ & 0,640 & 2,00 & $\% 10$ & 4 & $\% 30$ & 12 & $\% 60$ & 24 & 15 \\
\hline 0,864 & 0,640 & 2,00 & $\% 25$ & 10 & $\% 10$ & 4 & $\% 65$ & 26 & 16 \\
\hline $1,45^{-}$ & 0,671 & 2,60 & $\% 15$ & 10 & $\% 10$ & 6 & $\% 75$ & 34 & 17 \\
\hline
\end{tabular}

يتضح من الجدول (4) أن النسب المئوية لعبارات المحور الأول الأول نوافر الإمكانات

المادية والبشرية للمنشأت الرياضية تراوحت في الإجابة بنعم بين (35\%، 90\%) بينما نراوحت في 
الاجابة الي حد ما بين (5\%، 30\%) فيما نزاوحت في الإجابة لا بين (صفر \%، 35\%) وتفاوتت قيم المتوسطات الحسابية ما بين (1,60، 2,80)، وتزاوح الإنحراف المعيارى ما بين (0,357، 0,877)، انحصرت معاملات الالتواء ما بين (+3، -3)، مما يدل علي اعتدالية البيانات. تعزى الباحثة ذلك إلى أن الإمكانات الرياضية مطلباً أساسياً لممارسة غالبية الأنشطة الرياضية بل مجملها بدليل أنه لا يمكن ممارسة أب نشاط رياضي إلا بتوفر الإمكانات الرياضية سواءً كانت منشأة رياضة أم أداة رياضية. وتتير الباحثة إلى أن الرياضة نستهدف رفع قدرات الإنسان وتدعيم طاقاته الحركية والذهنية، مما دفع الدول المتقدمة إلى نشر ممارسة الرياضة والألعاب الرياضية والنشاط الرياضى وخصوصاً اللياقة البدنية وتوزيع الميزانيات الرياضية على هذه الأنشطة بسخاء وإيجاد الحلول الايجابية لرفع مستوى اللياقة البدنية للأفراد وتوفير الصحة واللياقة البدنية وإيجاد القاعدة العريضة من الممارسين لهذه الأنشطة من بين مختلف القطاعات داخل الدولة. وإن نوافر المنشأت الرياضية داخل المدن والأحياء السكنية يؤدي إلى سهولة رفع اللياقة البدنية لأفراد المجتمع وإن تواجد الإمكانات يوفر الوقت والجهد لكل من أفراد المجتمع والمدربين. ومما لا شك فيه أن المنشأت الرياضية على غرار مختلف المنشآت الأخرى وفي كل مجالات الحياة قد شهدت نطوراً كبيراً واتساعاً في حجمها وتعددًا في وظائفها بشكل يسندعي أن تكون لتلك المنشأت إدارة رياضية، هذه الأخيرة أضحت أحد علوم الرياضة الحديثة، إذ من السهل بناء وتثييد المنشآت الرياضية، لكن من الصعب وجود إدارة سليمة نقوم بتسييرها. وتمثل المنشأت الرياضية الجهاز الرئيسي لتسيير النشاطات الرياضية وتعمل على تطويرها وفق الإمكانيات المنوفرة لديها تحت إدارة تسهر على تحقيق أهدافها، فالمنشأة الرياضية كما يرى لرئي البعض هي بمثابة الواقع المادي المؤسساتي الذي يتعهد الرياضة.

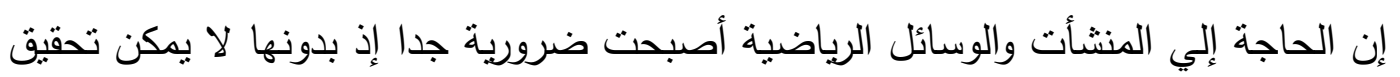

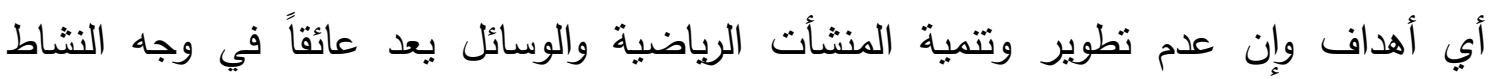
الرياضي، وإنه من الضروري استتباط طرائق ووسائل جديدة تفسح المجال لاستخدام أدوات ومعدات

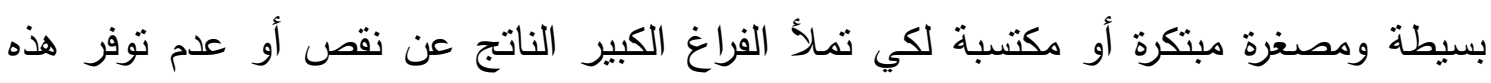
التجهيزات. 
وتوفر هذه المنشآت والوسائل الرياضية معناه زيادة الإقبال والمشاركة إذ ما توفرت فإنها سنظهر الوجه الحقيقي للرياضة من خلال تحقيق أهداف المنشأت الرياضية.

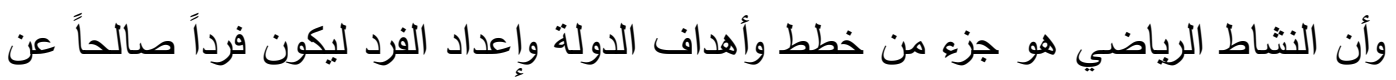

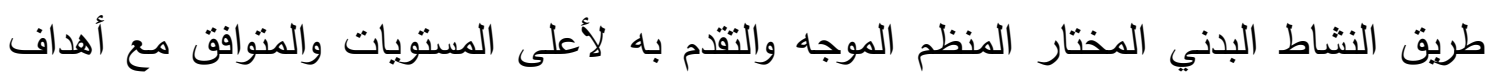
الدولة ولابد من توفير كافة السبل والإمكانات ليتمكن الفرد من ممارسة الأنشطة الرياضية وهذا يتفق مع دراسة سعد عبد الله (2013م) (7) حيث تذكر الدراسة إن توافر الإمكانات يعد أحد العناصر الأساسية المؤثرة في نجاح المنشأت الرياضية في نشر ممارسة الرياضة، حيث لا غنى عن وجود صالات وملاعب وأدوات رياضية يستطيع اللاعبين استخدامها بكل يسر وسهولة وأن تكون هذه الصالات والمنشأت قانونية ومعتدة. عرض ومناقشة نتائج المحور الثاني طريقة إدارة وتنظيم الأنثطة الرياضية بالمنشأت الرياضية على مشاركة أفراد المجتمع فى الأنثطة الرياضية: جدول (5)

التكرار والنسب المئوية المتوسط الحسابي والإنحراف المعياري ومعامل الالتواء لعبارات المحور

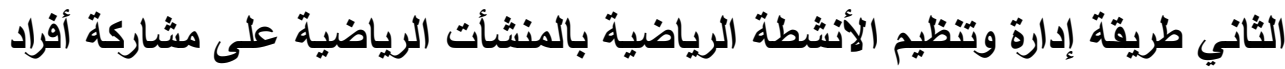
المجتمع فى الأنثطة الرياضية

$40=\dot{0}$

\begin{tabular}{|c|c|c|c|c|c|c|c|c|c|}
\hline \multirow{2}{*}{ معامل الالتواء } & \multirow{2}{*}{ المعيارى } & \multirow{2}{*}{ الحسابى } & \multicolumn{2}{|c|}{ ע } & \multicolumn{2}{|c|}{ إلى حد ما } & \multicolumn{2}{|c|}{ نعم } & \multirow{2}{*}{ r } \\
\hline & & & $\%$ & S & $\%$ & 5 & $\%$ & كs & \\
\hline $0,640-$ & 0,764 & 2,325 & $\% 20$ & 8 & $\% 10$ & 4 & $\% 70$ & 28 & 1 \\
\hline $0,684-$ & 0,671 & 2,40 & $\% 10$ & 4 & $\% 20$ & 8 & $\% 70$ & 28 & 2 \\
\hline $0,099-$ & 0,588 & 2,25 & $\% 25$ & 10 & $\% 10$ & 4 & $\% 65$ & 26 & 3 \\
\hline $01,033^{-}$ & 0,679 & 2,50 & $\% 10$ & 4 & $\% 30$ & 12 & $\% 60$ & 24 & 4 \\
\hline $0,508^{-}$ & 0,750 & 2,27 & $\% 10$ & 4 & $\% 40$ & 16 & $\% 50$ & 20 & 5 \\
\hline $0,384-$ & 0,733 & 2,22 & $\% 40$ & 15 & $\% 30$ & 10 & $\% 40$ & 15 & 6 \\
\hline 0,684 & 0,671 & 1,60 & $\% 10$ & 4 & $\% 40$ & 16 & $\% 50$ & 20 & 7 \\
\hline 0,214 & 0,648 & 1,80 & $\% 10$ & 4 & $\% 35$ & 12 & $\% 55$ & 24 & 8 \\
\hline $0,60^{-}$ & 0,667 & 2,37 & $\% 10$ & 4 & $\% 40$ & 16 & $\% 50$ & 20 & 9 \\
\hline $0,177-$ & 0,619 & 2,22 & $\% 10$ & 4 & $\% 30$ & 12 & $\% 60$ & 24 & 10 \\
\hline $0,538^{-}$ & 0,784 & 2,27 & $\% 25$ & 10 & $\% 10$ & 4 & $\% 65$ & 26 & 11 \\
\hline
\end{tabular}




\begin{tabular}{c|c|c|c|c|c|c|c|c|c}
\hline \hline $0,531-$ & 0,723 & 2,30 & $\% 40$ & 15 & $\% 30$ & 10 & $\% 40$ & 15 & 12 \\
\hline $0,115-$ & 0,607 & 2,20 & $\% 30$ & 10 & $\% 40$ & 15 & $\% 40$ & 15 & 13 \\
\hline $0,829-$ & 0,640 & 2,47 & $\% 10$ & 4 & $\% 40$ & 16 & $\% 50$ & 20 & 14 \\
\hline $1,013-$ & 0,715 & 2,47 & $\% 30$ & 10 & $\% 40$ & 15 & $\% 40$ & 15 & 15 \\
\hline $0,384-$ & 0,733 & 2,22 & $\% 10$ & 4 & $\% 40$ & 16 & $\% 50$ & 20 & 16 \\
\hline 0,684 & 0,671 & 1,60 & $\% 40$ & 15 & $\% 30$ & 10 & $\% 40$ & 15 & 17 \\
\hline \hline
\end{tabular}

يتضح من الجدول (5) أن النسب المئوية لعبارات المحور الثاني طريقة إدارة وتتظيم الأنشطة الرياضية بالمنشأت الرياضية على مشاركة أفراد المجتمع فى الأنشطة الرياضية نراوحت في الاجابة بنعم بين (40\%، 70\%) بينما تراوحت في الاجابة الي حد ما بين (10\%، 40\%) فيما تراوحت في الاجابة لا بين (10\%، 40\%) وتفاوتت قيم المنوسطات الحسابية ما بين (2، 50، 1,60) وتراوح الانحراف المعيارى لها ما بين (-0,60، 0,684)، انحصرت معاملات الالتواء ما بين (+3، -3)، مما يدل علي اعتدالية البيانات. وتعزى الباحثة ذلك إلى أن الرياضة ممارسة حضارية واجتماعية وصحية كانت ومازالت تعكس التطور والتقام للأمم والثعوب كونها تخص أهم مكونات المجتمع والحياة وهو الإنسان فكراً

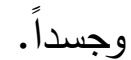

وبدون الإدارة الجيدة لا يمكن للمنشأت الرياضية أن تحقق أهدافها وأهداف ممارسين النشاط الرياضى من حيث تتمية اللياقة البدنية لدى الأفراد، حيث أن الإدارة الجيدة تعمل على استقطاب الهي الكوادر التدريبية والفنية والعناصر الأخرى التي نسهم في بناء وتطوير اللباقة البدنية لدى الأفراد وتعتبر المنشآت الرياضية الدعامة الأساسية لتكريس حق ممارسة الرياضة ووسيلة رئيسية لتتمية اللياقة البدنية لدى أفراد القوات المسلحة داخل الوحدات. وهذا يتفق مع دراسة بورزامة رايح (2014م) (6) حيث أوضحت أن دور العملية الإدارية في تجسيد وتفسير وتطبيق الأهداف والسياسات واستراتيجيات المنشأت الرياضية وأن تنفيذ القرارات ونهايتها مرتبطة ارتباطاً وثثقاً بمبادئ وأحكام وقواعد أنشئها القانون وبالتالى تطبيق عناصر العطلية الإدارية وفق معايير علمية ددروسة برجع بالإيجاب على نجاح وفعالية العملية الإدارية، مما بساهم في اقبال الأفراد على المنشأت الرياضية للممارسة النشاط الرياضى. 
عرض ومناقثة نتائج المحور الثالث برامج الأنثطة الرياضية داخل المنشأت الرياضية: جدول (6)

التكرار والنسب المئوية المتوسط الحسابي والإنحراف المعياري ومعامل الإلتواء لعبارات

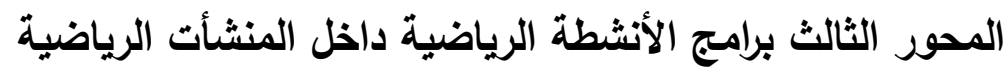

$40=\dot{0}$

\begin{tabular}{|c|c|c|c|c|c|c|c|c|c|}
\hline \multirow{2}{*}{ معامل الالتواء } & \multirow{2}{*}{ الانحراف } & \multirow{2}{*}{ الحسابى } & \multicolumn{2}{|c|}{$y$} & \multicolumn{2}{|c|}{ إلى حد ما } & \multicolumn{2}{|c|}{ نعم } & \multirow[b]{2}{*}{$p$} \\
\hline & & & $\%$ & ك & $\%$ & S & $\%$ & ك & \\
\hline $0,907-$ & 0,464 & 2,700 & |صفر \% | & صفر & $\% 5$ & 2 & $\% 95$ & 38 & 1 \\
\hline $0,684-$ & 0,671 & 2,400 & \begin{tabular}{|l|}
$\% 25$ \\
\end{tabular} & 10 & $\% 10$ & 4 & $\% 65$ & 26 & 2 \\
\hline $0,602-$ & 0,790 & 2,300 & $\% 15$ & 6 & $\% 20$ & 8 & $\% 65$ & 26 & 3 \\
\hline $0,907-$ & 0,464 & 2,700 & \begin{tabular}{|l|}
$\% 10$ \\
\end{tabular} & 3 & $\% 15$ & 5 & $\% 80$ & 32 & 4 \\
\hline $1,559-$ & 0,405 & 2,800 & \begin{tabular}{|l|}
$\% 15$ \\
\end{tabular} & 6 & $\% 20$ & 8 & $\% 65$ & 26 & 5 \\
\hline $1,559-$ & 0,405 & 2,800 & \%25 & 10 & $\% 10$ & 4 & $\% 65$ & 26 & 6 \\
\hline $2,772-$ & 0,607 & 2,800 & $\% 10$ & 4 & $\% 30$ & 12 & $\% 60$ & 24 & 7 \\
\hline $0,080^{-}$ & 0,545 & 1,900 & $\% 25$ & 10 & $\% 10$ & 4 & $\% 65$ & 26 & 8 \\
\hline 0,602 & 0,790 & 1,700 & $\% 20$ & 8 & $\% 10$ & 4 & $\% 70$ & 28 & 9 \\
\hline $0,907-$ & 0,464 & 2,700 & $\% 5$ & 2 & $\% 5$ & 2 & $\% 90$ & 36 & 10 \\
\hline $2,772-$ & 0,303 & 2,900 & $\% 5$ & 2 & $\% 10$ & 4 & $\% 85$ & 34 & 11 \\
\hline $0,357-$ & 0,757 & 2,200 & $\% 20$ & 8 & $\% 10$ & 4 & $\% 70$ & 28 & 12 \\
\hline
\end{tabular}

يتضح من الجدول (6) أن النسب المئوية لعبارات المحور الثالث برامج الأنشطة الرياضية داخل المنشأت الرياضية تزاوحت في الاجابة بنعم بين (60\%، 95\%) بينما تراوحت في الاجابة الي حد ما بين (5\%، 30\%) فيما تراوحت في الاجابة لا بين (صفر \%، 25\%). وتفاوتت قيم المتوسطات الحسابية ما بين (1,700، 2,900)، وتراوح الانحراف المعيارى لها ما بين (0,080، 0,602)، انحصرت معاملات الالتواء ما بين (+3، -3) مما يدل علي اعثدالية البيانات. وتعزى الباحثة ذلك إلى أن برامج الأنثطة الرياضية داخل المنشأت الرياضية هي كل ما يمكن أن بساهم في تحقيق هدف من أهداف المنشأت الرياضية من نسهيلات وملاعب وأجهزة وأدوات وميزانية وظروف مناخية وجغرافية ومعلومات وإطارات متخصصة متبعين الأسلوب العلمي للإدارة بجميع عناصرها من أجل تحقيق تلك الأهداف. 
وتلعب برامج الأنشطة الرياضية دوراً كبيراً في سير المنشأت الرياضية وتساهم في نظويرها وتعمل على تحقيق أهدافها التي من بينها الإسهام في عملية رفع اللياقة البدنية لاى فرد المجتمع لئه وتكوينه والعمل على رفع مستواه من خلال توفير الوسائل اللازمة والظروف الأساسية التي تساعد على تطويره والمساعدة على نشر الروح الرياضية وذلك بفسح المجال لأقصى عدد ممكن من أفراد المجتمع لممارسة النشاطات البدنية والرياضية وتكوين الرياضيين وتحسين مستواهم وتجديد معارفهم واستقبال الرياضيين من المنتخبات المحلية والوطنية ووضع الوسائل الضرورية تحت تصرفهم. وهذا يتفق مع دراسة كيم Kim (1997م) (20) حيث أوضحت الدراسة أهمية وضع برامج الأنشطة الرياضية عموماً حيث نجد أنه كلما توافرت برامج الأنشطة الرياضية كلما سهل ذلك من

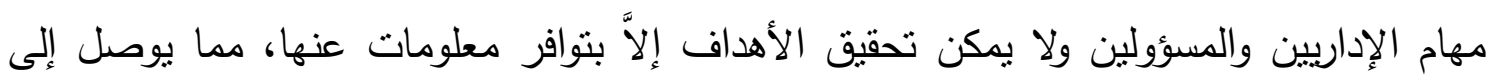
مستويات عليا وكلما كانت هناك دراية بالمعلومات كان هناك استخدام أمثل للإمكانات الأخرى. الإستتتاجات والتوصيات:

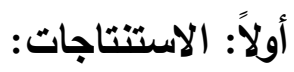
- المنشأت الرياضية لها تأثثر ايجابي على أفراد المجتمع لممارسة النشاط الرياضى. - - المنشأت الرياضية تمنح أفراد المجتمع الحرية الكاملة في اختيار الأنشطة الممارسة. - - تنوافر في المنشأت الرياضية كافة الأدوات والأجهزة الخاصة بممارسة الأنشطة الرياضية. - المنثأت الرياضية تحرص على استمرارية النظوير والتدريب الهادف لأفراد المجتمع. - تضع المنشأت الرياضية برامج تدريبية لعناصر اللياقة البدنية المتخصصة لأفراد المجتمع. ثانياً: التوصيات: - - يجب أن توفر المنثأت الرياضية بيئة صحية لأفراد المجتمع. - يجب على المنشأت الرياضية أن نتظم برامج الأنشطة الرياضية طبقاً لبرامج الأنشطة الرياضية بالأندية الرياضية والإتحادات الرياضية. - - يجب أن نوظف المنشأت الرياضية إمكانياتها لتحقيق أهداف برامج الأنشطة الرياضية الخاصة بالهيئة العامة للشباب والرياضة. 


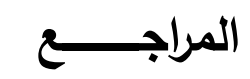

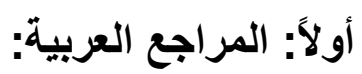

ال

1 - إبراهيم عبد المقصود

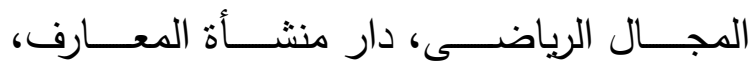

(2012)

$$
\text { الإسكندرية. }
$$

2. إبراهيم عبد المقصود وحسن الموسـوعة العلميـة لـلإدارة الرياضية، الإمكانـات

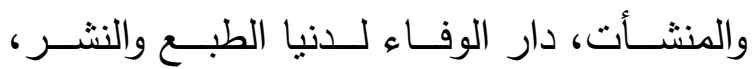

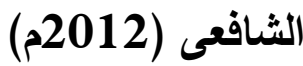

$$
\text { الإسكندرية }
$$

3. إبراهيم مروان (2015م) الإدارة والتنظيم والتنربيـة واليرياضـية، دار الفكر للطباعة والنشر ، والتوزيع، وعمان.

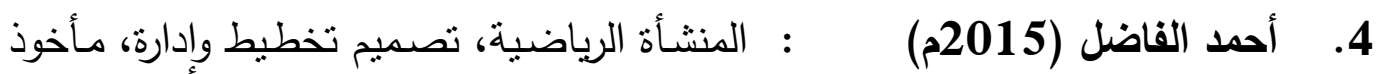

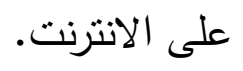

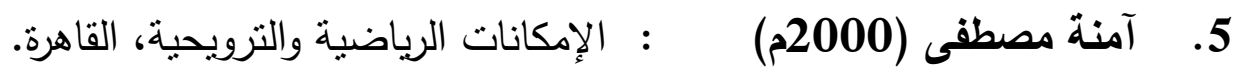

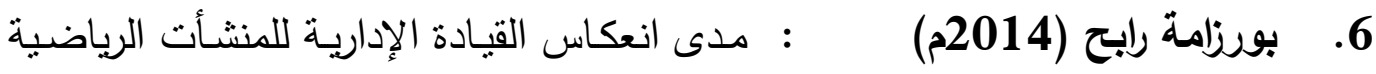

على نجاحـة المردود الرياضس، رسـالة دكتوراه،

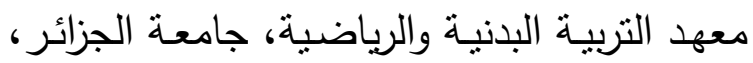

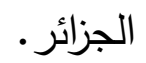

(

7. الثرقية بالمملكة العربية السعودية، رسالة دكتوراه،

جامعة الملك سعود، المملكة العربية السعودية.

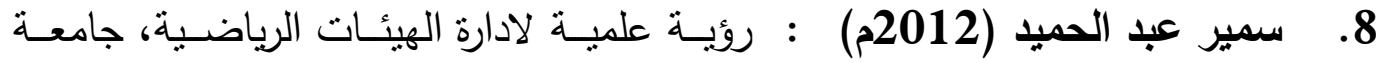

$$
\text { الملك سعود، الرياض. }
$$

9. عفاف عبد المنعم درويش الإمكانات في التربية الرياضية، منشأة المعارف، المباض

$$
\text { الإسكندرية. }
$$

10. مساعد الهارون (2013م) الإدارة في الدجـال الرياضـى، مؤسسـة الكويـت للتقدم العلمى، الكويت.

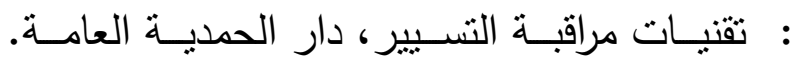




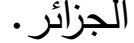

$$
\begin{aligned}
& \text { : المنشأت الثبابية والرياضية، إدارة الاعلام والنشر } \\
& \text { بوكالة شؤون الثباب، الكويت. }
\end{aligned}
$$

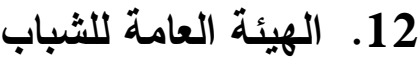$$
\text { والرياضة (12015م) }
$$

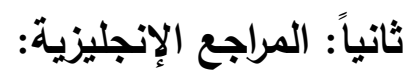

13. Bank, Johan (2000) : The essence of Total Quality Management 2nd.ed, Pearson education limited, Edinburgh Gate, Harlow, England.

14. Besterfield, Dale : Total Quality Management 3rd.ed, H.; Besterfield - Pearson education (Singapore) Michna, Carol; pte.Ltd., Indian Branch.

Besterfield, Glent

H., Besterfield -

Sacre, Mary (2005)

15. Coyle-Shapiro, J.\& : The role of individual differences in Morrow, P.(2003) employees adoption of TQM orientation. Journal of Vocational behavior, 62:320-340., [online], London: LSE Research online.

16. Dean, J.W.\& : Management theory and Total Bowen, D.E.(1994) Quality: Improving research and practice through theory development. Academy of Management Review,19,392-481.2nd.ed.

17. Defrance Jacque : Sociologie de sport, edition de la (2013) decouverte Paris.

18. Hashmi, khurram : Introduction and Implementation of (2005) Total Quality Management, http://www.isixsigma.com, from goole.com Retrieved on 30/09/2006.

19. Karajewisky L.J.\& : Operation Management: Strategy and Ritz Man K.P.(1996) analysis, 4th.ed, Addison wisely pub. Co.

20. Kim, Heung Sik : Sport management competencies for (1997) sport centers in the reupublic of Korea, United States Sport Academy. 
21. Robbins, Stephen $\mathbf{P}$ : Management, 8th.ed., Pearson \& Coulter, Mary Education, Inc., Upper saddle River, (2005)

22. Roche, M. (2014) : Mega-events and Modernity (London: Routledge).

مستخلص البحث : تحرص دولة الكويت على إنثاء العديد من المنشأت الرياضية فى كل المحافظات والمدن المختلفة ويتتوع إنثاء هذه المنشأت الرياضية ما بين المنشأت الرياضية القانونية والأولمبية لإقامة البطولات الرياضية ومنشأت رياضية لممارسة الرياضة الحرة للهواة ويجب على المجتمع المحلى وعلى المنظمات المجتمعية الاهتمام بهذه المنشأت والعمل على المى تطويرها وتتميتها من خلال إستخدام أهداف وخصائص ووظائف منهج إدارة الجودة. وذللك لأن منهج إدارة الجودة منهج إدارى يهتم بتطوير وتتمية جميع العمليات الإدارية والفنية وكذللك الإمكانيات المادية داخل المؤسسات والمنظمات المختلفة.

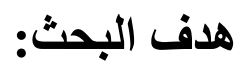
يهذف البحث إلى نطوير المنشأت الرياضية بدولة الكويت من خلال المشاركة المجتمية فى اطار تطبيق معايير جودة المنشأت.

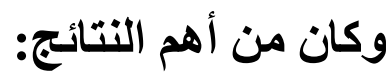

• المنشأت الرياضية لها تأثثر ايجابي على أفراد المجتمع لممارسة النشاط الرياضى. • المنشأت الرياضية تمنح أفراد المجتمع الحرية الكاملة في اختبار الأنشطة الممارسة. • تنوافر في المنشأت الرياضية كافة الأدوات والأجهزة الخاصة بممارسة الأنشطة الرياضية.

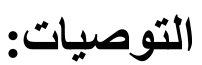
• يجب أن نوفر المنثأت الرياضية بيئة صحية لأفراد المجتمع.

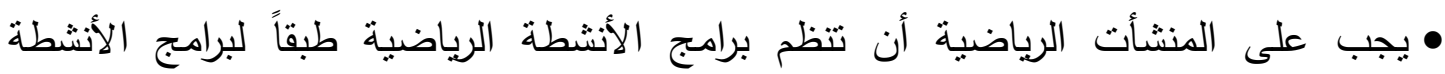
الرياضية بالأندية الرياضية والإتحادات الرياضية.

• يجب أن توظف المنشأت الرياضية إمكانياتها لتحقيق أهداف برامج الأنشطة الرياضية الخاصة بالهيئة العامة للثباب والرياضة. 


\section{The Research Abstract}

The State of Kuwait is keen to establish many sports facilities in all governorates and different cities. The establishment of these sports facilities varies between legal and Olympic sports facilities for the establishment of sports championships and sports facilities for the free exercise of amateur sports. The local community and community organizations must pay attention to these facilities and work to develop and develop them through Use the objectives, characteristics and functions of the quality management approach.

This is because the quality management approach is an administrative approach concerned with developing and developing all administrative and technical processes as well as the material capabilities within the various institutions and organizations.

\section{Research objective:}

The research aims to develop sports facilities in the State of Kuwait through community participation in the context of applying the standards of facility quality.

\section{Among the most important results:}

- Sports facilities have a positive impact on community members to practice sporting activity.

- Sports facilities give community members complete freedom to choose the activities they practice.

- The sports facilities have all the tools and devices for practicing sports activities.

\section{Recommendations:}

- Sports facilities must provide a healthy environment for community members.

- Sports facilities must organize sports activities programs according to the sports activities programs in sports clubs and sports federations.

- Sports facilities should employ their capabilities to achieve the goals of the sports activities programs of the General Authority for Youth and Sports. 


\section{مرفق (1)}

\section{تطوير المنشأت الرياضية بدولة الكويت من خلال المشاركة المجتمعية فى اطار تطبيق معاييز جودة المنشأت}

عزيزى موجه التربية البدنية/ تحية طيبة ويعد،،،

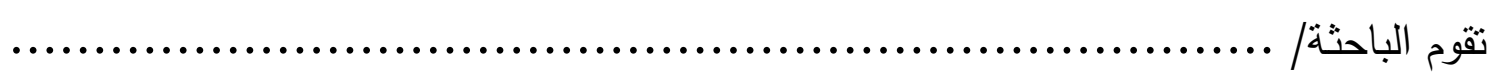
بانتاج بحث علمى فى أثر منظمات المجتمع المدني والجمعيات الوطنية والأهلية بدولة الكويت فى الكى

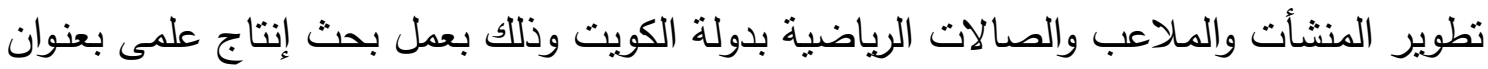
تطوير المنشأت الرياضية بدولة الكويت من خلال المشاركة المجتمعية فى اطار تطبيق معايير جودة المنشأت. • الرجاء من سيادنكم قراءة كل عبارة جيداً أو أجب عليها بما يتتاسب مع اتجاهك الحقيقى نحوها وذللك بوضع علامة (ل ) أمام (نعم). • اذا كانت العبارة تتطبق عليك بدرجة منوسطة ضع علامة (ل) أمام (إلى حد ما). • اذا كانت العبارة لا تتطبق عليك فضع علامة (ل) أمام (لا). رجاء مراعاة انه لا توجد اجابات صحيحة وأخرى خاطئة وإنما المهم هو صدق اجابتك مع

وأثنكركم على حسن تعاونكم الصادق،،،

\section{الباحثة}




\begin{tabular}{|c|c|c|c|c|}
\hline ע & مالِى حـ & ن تعم & 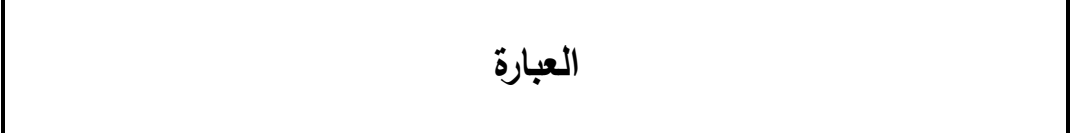 & م \\
\hline & & & المحور الأول: توافر الإمكانات المادية والبشرية للمنشأت الرياضية. & \\
\hline & & & |لمشـاركة في الأنشطة البدنية. & 1 \\
\hline & & & |المنشأت الرياضية بالمدينة أو الحى مهيئة لممارسة الأنشطة البدنية. & 2 \\
\hline & & & الأنشطة البدنية. & 3 \\
\hline & & & |لرياضية. تشجيع من القادة داخل المنشأت الرياضية على المشاركة في الأنشطة & 4 \\
\hline & & & تتوفر داخل المنشأت الرياضية ملاعب منتوعة لإقامة النشاط البدني. & 5 \\
\hline & & & لينوفر داخل المنشأت الرياضية قاعة مغلقة لممارسة النشاط البدنى. & 6 \\
\hline & & & توجد أدوات مساعدة لممارسة النشاط البدني. & 7 \\
\hline & & & توجد بالمنشأت الرياضية ملاعب عديدة ومتتوعة قانونية ومصغرة. & 8 \\
\hline & & & الملاعب والمنشأت كافية لممارسة النشاط البدنى لجميع أفراد المجتمع. & 9 \\
\hline & & & نظام العمل داخل المنشأت الرياضية يؤثر سلباً على ممارسة النشاط البدنى. & 10 \\
\hline & & & توجد ندرة في المنشأت الرياضية الخاصة بالأحباء السكنية. & 11 \\
\hline & & & 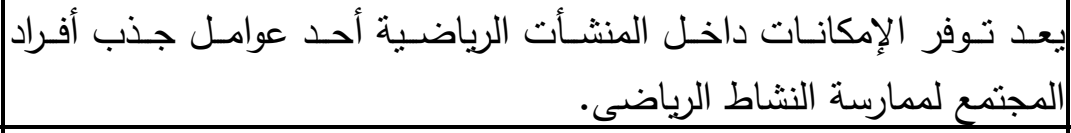 & 12 \\
\hline & & & 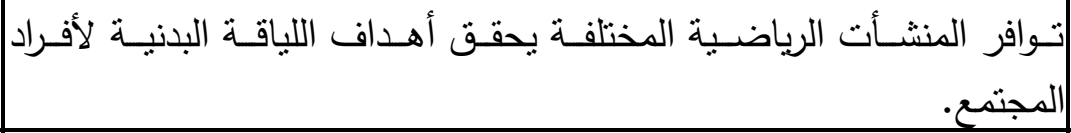 & 13 \\
\hline & & & |فوالة. المنشأت الرياضية يساهم في رفع اللياقة البدنية لأفراد المجتمع بصورة & 14 \\
\hline & & & 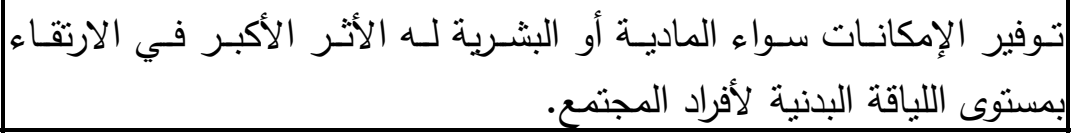 & 15 \\
\hline & & & 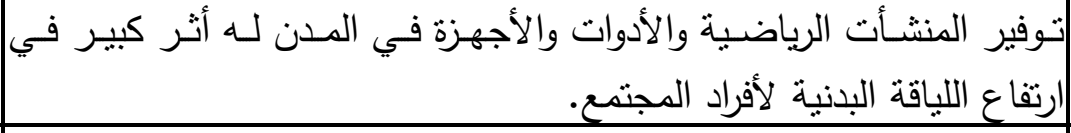 & 16 \\
\hline & & & تواجد المنشأت الرياضية بالقرب من الأحياء السكنية يوفر الوقت والجهد. & 17 \\
\hline \multicolumn{5}{|c|}{ |لمجتمع في الأنشطة الرياضي: طريقة إدارة وتنظيم الأنشطة الرياضية بالمنشأت الرياضية على مشاركة أفراد } \\
\hline & & & رواد النشاط بالمنشأت الرياضية يسهلون إجراءات تنفيد الأنشطة الرياضية. & 1 \\
\hline & & & مواعيد إقامة الأنشطة الرياضية تعيق مشاركتي فيها. & 2 \\
\hline & & & جداول تتظيم الأنشطة الرياضية تعيق مشاركتي فيها. & 3 \\
\hline
\end{tabular}




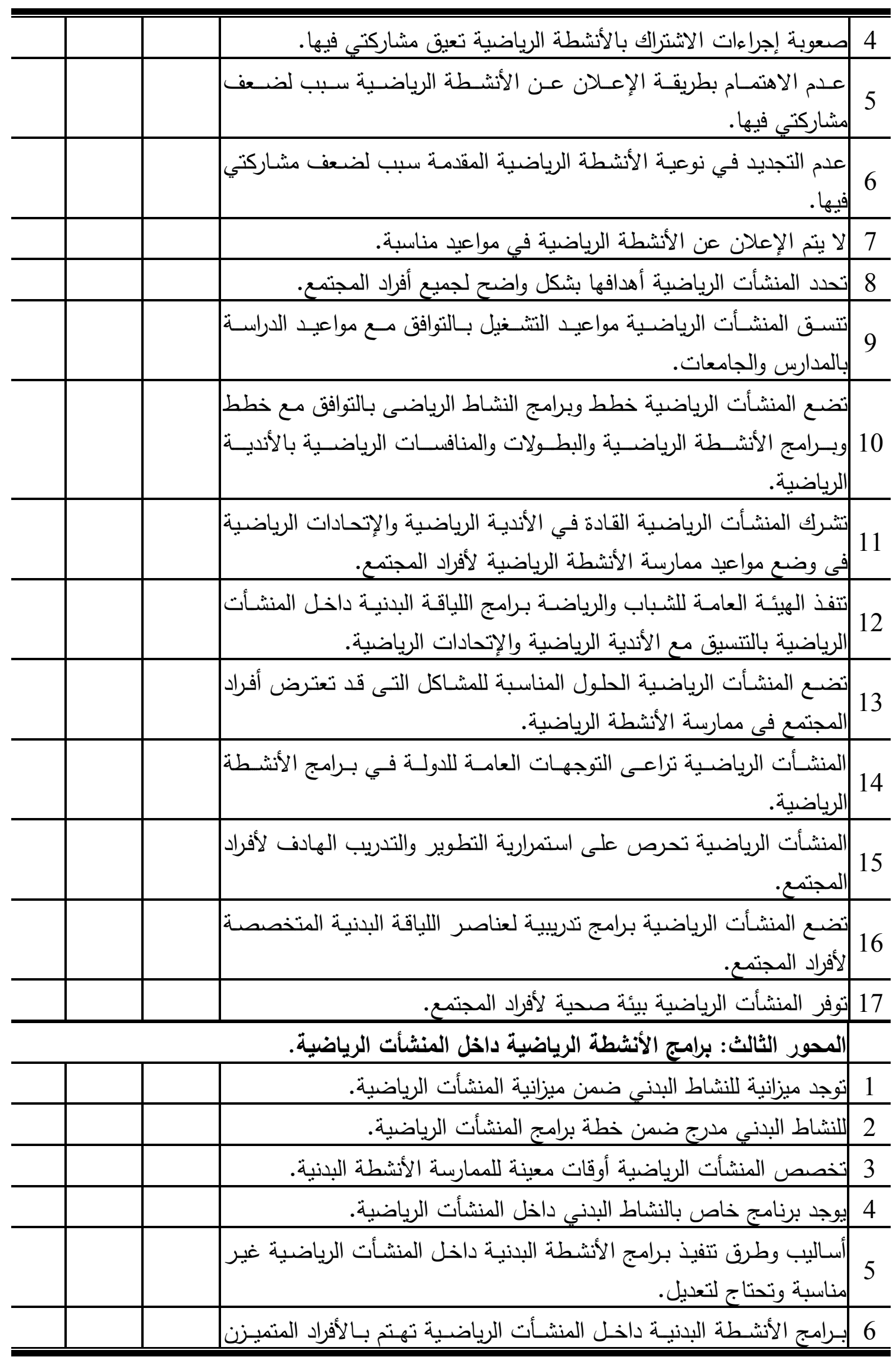




\begin{tabular}{|c|c|c|c|}
\hline & & & رياضياً. \\
\hline & & & |لرياضية. المنشـأت الرياضية خطط الأنشطة الرياضية بالتتسيق مـع الأنديـة \\
\hline & & & | توجيئة العامة للشباب ورامج الأنشطة الرياضية داخل المنشأت الرياضية من قبل| \\
\hline & & & 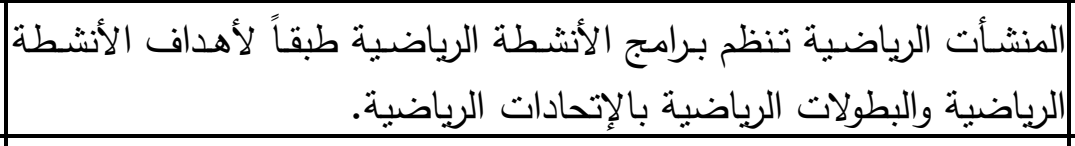 \\
\hline & & & |الأندية الرياضية. الرياضية تتظم برامج الأنشطة الرياضية طبقاً لبرامج التدريب داخل| \\
\hline & & & 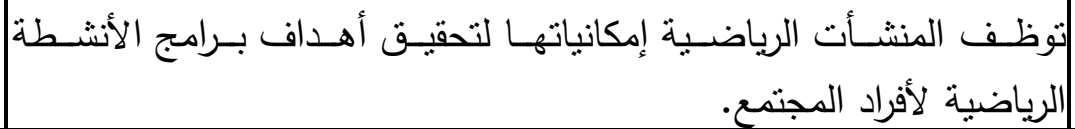 \\
\hline & & & حتوى المنثأت الرياضية على العديد من أنثطة اللياقة البدنية المختلفة. \\
\hline
\end{tabular}

